\title{
Gall Bladder Ultrasonographic Changes in Children with Chronic Liver Diseases
}

\author{
OSAMA ABUEL NAGA, M.D. and AMR M. ABDEL SAMAD, M.D.
}

The Department of Radiology, Faculty of Medicine, Ain Shams University

\begin{abstract}
Background: Chronic liver diseases in the pediatric age group are rather a common problem with minimal symptoms yet carries the risk of considerable morbidity and even mortality, especially in developing countries. Chronic liver diseases are diagnosed if clinical or laboratory data of liver dysfunction persist for more than six months.

Aim of Study: Our study aimed to evaluate the gall bladder ultrasonographic changes in children with chronic liver diseases in comparison to healthy children in Children Hospital Ain Shams University Hospital.

Material and Methods: This study included one hundred twenty-five children, including one hundred chronic liver disease patients (62 males and 38 females) and twenty-five healthy children as controls. The age ranges from 0.25 to 18 years. All children underwent clinical assessment, laboratory investigations and gall bladder ultrasonography.
\end{abstract}

Results: The mean gall bladder anterior wall thickness in patients with gallstones is significantly higher than healthy controls $(p$-value $=0.006)$. The means of both fasting volume and contraction index were lower in patients with gallstones compared to both patients without gallstones and healthy controls yet they were statistically insignificant. The mean gall bladder anterior wall thickness in patients without gallstones is higher than healthy controls yet it was statistically insignificant.

Conclusion: Chronic liver disease in the pediatric age group is associated with gall bladder sonographic changes. Gall bladder anterior wall thickness was the most significant risk factor for the development of gallstones in children with chronic liver disease.

Key Words: Gall bladder-Ultrasonography - Chronic liver disease-Children.

\section{Introduction}

GALL stones are found in $10-20 \%$ of the general adult population while in chronic liver disease,

Correspondence to: Dr. Osama Abuel Naga, E-Mail: ooabuelnaga@hotmail.com there is 1.2 to 5 -fold increase in the frequency compared with the general poulation [1]. Gall Bladder (GB) and common bile duct stones have been increasingly diagnosed in the pediatric age group [2]. European studies in pediatric patients showed that the overall prevalence of 0.13 to $1.9 \%$ of gallstone disease in children up to 18 years of age [3]. The widespread, safety and feasibility of abdominal sonography led to an increase in the frequency of diagnosis of cholelithiasis and other gall bladder disorders in the pediatric age group [4] . Gall bladder stones are classified into cholesterol, pigment and mixed stones according to their chief constituents [5].

Chronic liver diseases in children are relatively common disorders with minimal symptoms but long-term risk of significant morbidity and mortality, particularly in developing countries. They are defined by the continuity of clinical or biochemical evidence of hepatic dysfunction for longer than six months [6]. Cirrhosis increases the possibility of gallstones formation. Also, the incidence of gallstone disease increases with the severity of the hepatic disorder. However, most cases are asymptomatic. When symptoms arise, morbidity and mortality are much higher than in non-cirrhotic cases [7].

Gallstones are seen in 33-46\% of cases with cirrhosis. Also, their occurrence is proportional to the duration and severity of the liver disease. Gallstones formation in hepatic patients might be attributed to autonomic neuropathy which accompanies advanced cirrhosis. This neuropathy leads to gall bladder impaired function as well as dysmotility of the sphincter of Oddi [8].

The aim of this study is to evaluate the gall bladder ultrasonographic changes in children with 
chronic liver diseases in comparison to healthy children in Children Hospital Ain Shams University Hospital.

\section{Material and Methods}

The Ain Shams University Ethical Committee, Cairo, Egypt, approved the study. All methods used in this study were approved by the Institutional Review Board (IRB) of the same university. Informed consent using language (Arabic dialect) was obtained from the caregivers of all participants. Parents were provided with a description of the potential benefits, the voluntary nature of the study, their right to withdraw without consequences, and the confidentiality of the information collected.

Study type:

This is a comparative cross-sectional casecontrol study.

\section{Patients:}

All subjects were recruited from Pediatric Hepatology Clinic Children Hospital Ain Shams University Hospital. The study was performed from June 2018 to June 2019.

The present study included 125 children aged from four months to 18 years. They were subdivided into two groups. Group I: 100 patients with chronic liver disease. The etiology of chronic liver disease in the patients (GI) is shown in (Table 1). Group II included 25 healthy age and sex-matched children to serve as a control group.

\section{Methods:}

All patients were evaluated with:

Full history taking with particular emphasis on sex age, at the onset of symptoms, duration and etiology of liver disease as well as symptoms of chronic liver disease (jaundice, bleeding tendency, hematemesis, melena, abdominal distension, encephalopathy and pruritis). Thorough clinical examination was carried out with anthropometric measurements including weight, height and Body Mass Index (BMI). Full clinical examination with a special emphasis on abdominal examination for signs of chronic liver disease and portal hypertension (jaundice, collateral circulation, fetor hepaticus, edema of the lower limb, spider naevi, ascites, palmar erythema, liver size and consistency and splenic size).
The following investigations were done for all participants: Complete Blood Count (CBC), reticulocyte count, complete liver function tests and lipid profile (serum cholesterol, triglycerides, LDL and HDL).

Ultrasonographic examinations: We used color Doppler ultrasonographic machine (GE, Logiq 9, using a $5 \mathrm{MHz}$ convex probe). All children were examined twice, the first time while fasting for six to eight hours and the second time 30-60 minutes after ingestion of a fatty meal. All were examined in supine, oblique and left lateral decubitus positions. Multiple views of the Gall Bladder (GB) were achieved at different imaging planes.

The ultra-sound findings include: Measurement of the thickness of the anterior wall of the GB Fig. (1), comment on the presence of sludge or lithiasis Fig. (2), the presence of varices in the GB wall as detected by the serpentine shape of the intra-mural vessels and by the venous flow using pulse duplex and color Doppler imaging, measurement of the GB, length (L) in longitudinal axis, width (W) and height $(\mathrm{H})$ in axial axis were done Fig. (3). The Fasting Volume (FV) was calculated. V $=\mathrm{r} / 6$ (L X $\mathrm{W} X \mathrm{H})$. The constant $\mathrm{r} / 6$ was reduced to 0.52 according to Dodds formula. The Residual Volume (RV) was calculated using the same measurements taken after a meal. The Contraction Index (CI) was calculated from the formula:

$$
\mathrm{CI} \%=\frac{\mathrm{FV}-\mathrm{RV}}{\mathrm{FV}} \mathrm{X} 100
$$

The contractility was classified as abnormal if less than $50 \%$.

\section{Statistical methods:}

The collected data was revised, coded, tabulated by using the Statistical Package for Social Science (SPSS; Version 20.0. Armonk, NY: IBM Corp). Student $t$-test and Wilcoxon Rank Sum test were used to assess the statistical significance of the difference between the two groups. Ranked Spearman correlation and Chi-square tests were used to evaluate the strength of association between every two variables among each group. The probability of error at 0.05 was considered significant. 


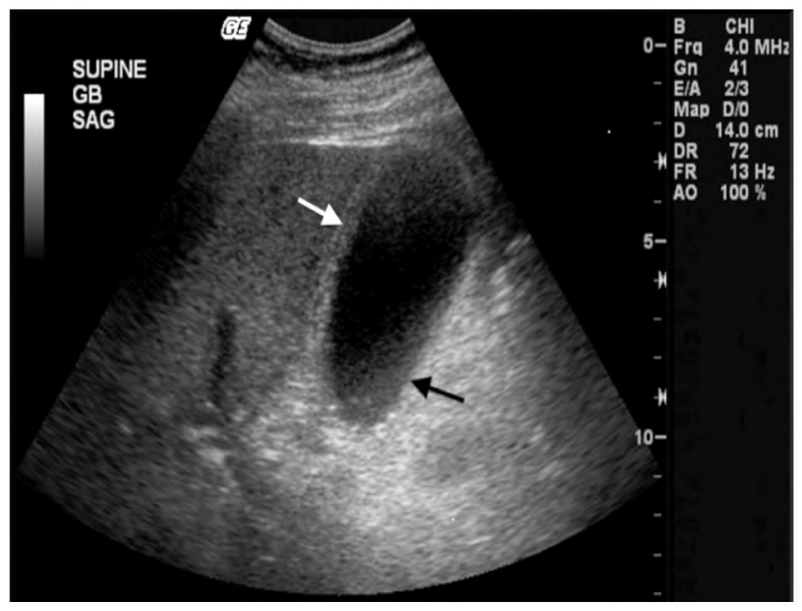

Fig. (1): Sonographic image of the gall bladder showing thickened anterior wall of the gall bladder.

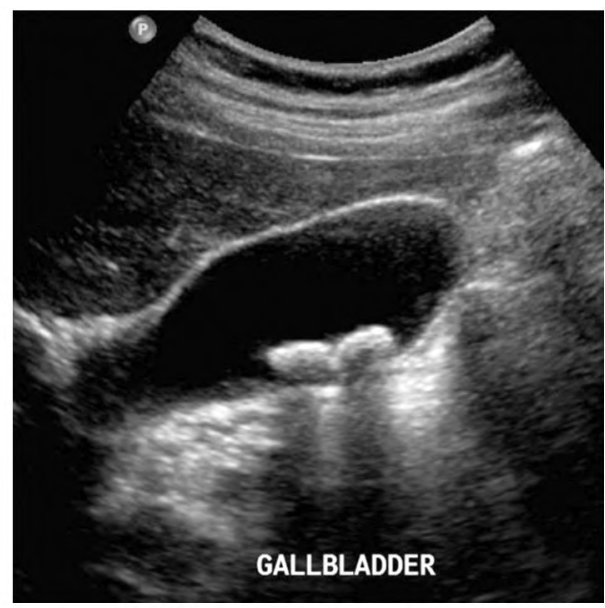

Fig. (2): Sonographic image of the gall bladder showing stones within.
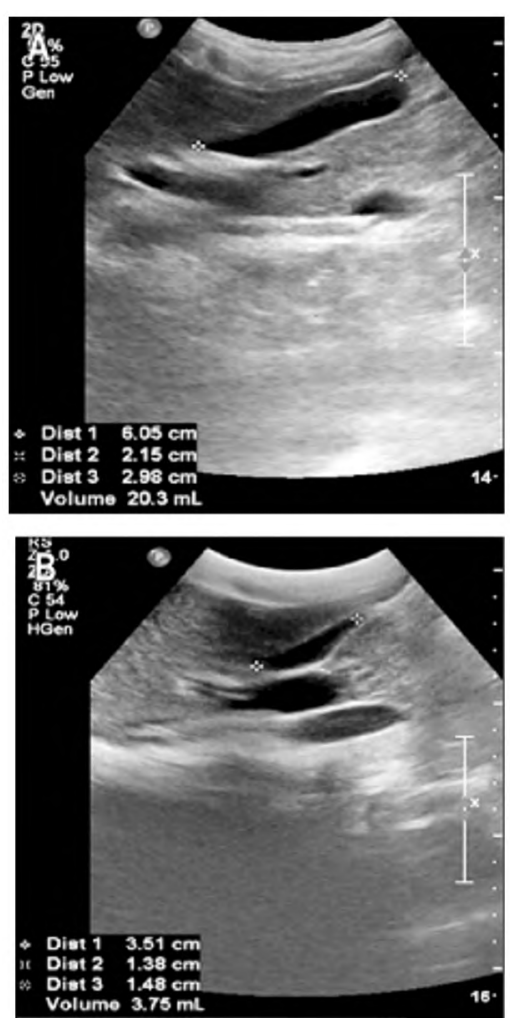

Results

The patient group (Group 1) included 100 patients with chronic liver disease recruited from Pediatric Hepatology Clinic Ain Shams University. They were 62 males and 38 females. Their ages ranged from 0.25 to 18 years with a mean of $8.8 \pm 5$ years. Table (1) shows the etiology of chronic liver disease in our series. The patients were classified according to modified Child-Pugh classification (Pugh et al., 1973) into class A: 74 patients (74\%), class B: 24 patients (24\%), and class C: 2 patients $(2 \%)$. They were further classified according to the presence of gallstones by abdominal ultra-
Fig. (3): Sonographic image of the gall bladder at both fasting and post prandial status showing normal contractility. sonography into cases with gallstones (Group 1a). They were 14 patients (14\%); nine males and five females, and (Group 1b) cases without gallstones including 86 patients (86\%) included 53 males and 33 females. There were no significant differences between both patients' groups (Group 1a and 1b) and controls (Group 2) as regards demographic data and anthropometric measurements. The mean GB anterior wall thickness and the mean residual volume were higher in gallstone group 1a compared to non-stone group $1 \mathrm{~b}$; however, the difference did not reach statistical significance. Besides, the means of fasting volume and contraction index were lower in group 1a compared to group $1 \mathrm{~b}$, yet 
again the difference did not reach statistical significance (Table 2). We found the mean GB anterior wall thickness in group 1a with gallstones is significantly higher than healthy controls in group 2 $(2.44 \pm 1.43$ versus $1.24 \pm 0.37 ; p=0.006)$ (Table 3 ); however, it was comparable between patients without stones in group $1 \mathrm{~b}$ and controls in group 2 (Table 4). The contraction index was less in the gall stones group 1a compared to controls yet; the difference did not reach statistical significance. We found that anterior wall thickness was the most significant risk factors for the development of gallstones in children with chronic liver disease.

Table (1): The etiology of chronic liver disease in the studied patient.

\begin{tabular}{lc}
\hline Diagnosis & Number (100) \\
\hline Hepatitis C virus & 27 \\
Autoimmune hepatitis & 10 \\
Congenital hepatic fibrosis & 8 \\
Chronic liver disease (unknown etiology) & 8 \\
Progressive familial intra-hepatic cholestasis & 8 \\
Portal vein thrombosis & 7 \\
Wilson disease & 7 \\
Glycogen storage disease & 5 \\
Neonatal hepatitis & 3 \\
Sclerosing cholangitis & 2 \\
Budd Chiari syndrome & 2 \\
Criggler Najar syndrome & 2 \\
Gall bladder stones (without underlying liver disease) & 2 \\
Other causes & 9 \\
\hline
\end{tabular}

Table (2): Comparison between patients with gall stones (G1a) and patients without gall stones (G1b) as regards ultrasound measurements.

\begin{tabular}{llcc}
\hline Parameter & $\begin{array}{c}\text { G1b } \\
(\mathrm{N}=86)\end{array}$ & $\begin{array}{c}\text { G1a } \\
(\mathrm{N}=14)\end{array}$ & $\begin{array}{c}p- \\
\text { value }\end{array}$ \\
\hline GB anterior wall thickness $(\mathrm{mm})$ & $1.79 \pm 1.56$ & $2.44 \pm 1.43$ & 0.074 \\
GB length at fasting condition $(\mathrm{cm})$ & $4.89 \pm 1.34$ & $4.73 \pm 2.01$ & 0.367 \\
GB length after meal (cm) & $3.63 \pm 1.08$ & $4.18 \pm 2.06$ & 0.714 \\
GB width at fasting condition $(\mathrm{cm})$ & $2.03 \pm 0.71$ & $2.26 \pm 1.37$ & 0.973 \\
GB width after meal (cm) & $1.35 \pm 0.54$ & $1.47 \pm 0.74$ & 0.894 \\
GB height at fasting condition $(\mathrm{cm})$ & $1.93 \pm 0.73$ & $1.85 \pm 0.65$ & 0.842 \\
GB height after meal $(\mathrm{cm})$ & $1.23 \pm 0.45$ & $1.43 \pm 0.77$ & 0.735 \\
Fasting volume $(\mathrm{ml})$ & $11.9 \pm 10.2$ & $9.85 \pm 10.46$ & 0.361 \\
Residual volume $(\mathrm{ml})$ & $4.1 \pm 4.9$ & $7.19 \pm 11.11$ & 0.859 \\
\hline
\end{tabular}

Table (3): Comparison between patients with gall stones (G1a) and controls (G2) as regards ultrasound measurments.

\begin{tabular}{llll}
\hline Parameter & \multicolumn{1}{c}{$\begin{array}{c}\mathrm{G} 1 \mathrm{a} \\
(\mathrm{N}=14)\end{array}$} & $\begin{array}{c}\mathrm{G} 2 \\
(\mathrm{~N}=25)\end{array}$ & $\begin{array}{c}p- \\
\text { value }\end{array}$ \\
\hline GB anterior wall thickness $(\mathrm{mm})$ & $2.44 \pm 1.43$ & $1.24 \pm 0.37$ & 0.006 \\
GB length at fasting condition $(\mathrm{cm})$ & $2.73 \pm 2.01$ & $4.90 \pm 1.41$ & 0.558 \\
GB length after meal $(\mathrm{cm})$ & $4.18 \pm 2.06$ & $3.7 \pm 1.33$ & 0.626 \\
GB width at fasting condition $(\mathrm{cm})$ & $2.26 \pm 1.37$ & $2.19 \pm 0.53$ & 0.545 \\
GB width after meal (cm) & $1.47 \pm 0.74$ & $1.38 \pm 0.44$ & 0.922 \\
GB height at fasting condition $(\mathrm{cm})$ & $1.85 \pm 0.65$ & $2.07 \pm 0.67$ & 0.32 \\
GB height after meal (cm) & $1.43 \pm 0.77$ & $1.23 \pm 0.45$ & 0.781 \\
Fasting volume (ml) & $9.85 \pm 10.46$ & $12.76 \pm 8.46$ & 0.14 \\
Residual volume $(\mathrm{ml})$ & $7.19 \pm 11.11$ & $3.82 \pm 4.09$ & 0.922 \\
Contractility index \% & $20.39 \pm 30.93$ & $69.18 \pm 14.8$ & 0.144 \\
\hline
\end{tabular}

Table (4): Comparison between patients without gall stones (G1b) and controls (G2) as regards ultrasound measurments.

\begin{tabular}{llll}
\hline Parameter & $\begin{array}{c}\text { G1b } \\
(\mathrm{N}=86)\end{array}$ & $\begin{array}{c}\text { G2 } \\
(\mathrm{N}=25)\end{array}$ & $\begin{array}{c}p- \\
\text { value }\end{array}$ \\
\hline GB anterior wall thickness $(\mathrm{mm})$ & $1.79 \pm 1.56$ & $1.24 \pm 0.37$ & 0.101 \\
GB length at fasting condition $(\mathrm{cm})$ & $4.89 \pm 1.34$ & $4.90 \pm 1.41$ & 0.963 \\
GB length after meal $(\mathrm{cm})$ & $3.63 \pm 1.08$ & $3.7 \pm 1.33$ & 0.732 \\
GB width at fasting condition (cm) & $2.03 \pm 0.71$ & $2.19 \pm 0.53$ & 0.209 \\
GB width after meal (cm) & $1.35 \pm 0.54$ & $1.38 \pm 0.44$ & 0.615 \\
GB height at fasting condition $(\mathrm{cm})$ & $1.93 \pm 0.73$ & $2.07 \pm 0.67$ & 0.357 \\
GB height after meal (cm) & $1.23 \pm 0.45$ & $1.23 \pm 0.45$ & 0.977 \\
Fasting volume (ml) & $11.9 \pm 10.2$ & $12.76 \pm 8.46$ & 0.338 \\
Residual volume (ml) & $4.1 \pm 4.9$ & $3.82 \pm 4.09$ & 0.668 \\
Contractility index \% & $62.5 \pm 20.7$ & $69.18 \pm 14.82$ & 0.229 \\
\hline
\end{tabular}

\section{Discussion}

Gall bladder diseases and gallstones are uncommon in infants and children but recently have been progressively diagnosed, mainly due to the frequent use and feasibility of abdominal ultrasonography [9]. In the present study, the patient group included 100 patients with chronic liver disease; there were 14 patients (14\%) having gallstones as diagnosed by abdominal ultrasonography. Our study aimed to evaluate the gall bladder ultrasonographic changes in children with chronic liver diseases in comparison to healthy children in Children Hospital Ain Shams University Hospital. In line with our results, Dooki et al., [10] found in his study conducted upon 66 children with gall stones that the most common predisposing factors of cholelithiasis were hemolytic diseases, hepatobiliary diseases and cystic fibrosis. As well, Karami et al., [11] stated that hemolytic diseases, hereditary blood disorders, and cirrhosis were among the main causes of cholelithiasis in children. Also, Zhang et al., [12] conducted a study on the prevalence of gallstone disease in Chinese patients with liver cirrhosis. They enrolled 90 compensated cirrhotic patients (Child-Pugh A), 180 decompensated cirrhotic patients (Child-Pugh B,C) and 300 controls. The study confirmed the high prevalence of cholelithiasis in liver cirrhosis $(23.7 \%)$ and the prevalence of gall stones in decompensated cirrhotic patients was higher than that of the compensated patients $(p<0.001)$. Similarly, Conte et al., [13] conducted a study to evaluate the frequency of gallstones and related risk factors in a large series of patients with cirrhosis. They reported that cirrhosis per se represented a major risk factor for gallstone formation whose prevalence $(29.5 \%)$ and incidence were far higher than reported in a general population from the same area. Aiming at finding the risk factors for developing stones in our cohort, we compared patients with gallstones to patients without gallstones as regards various demographic, 
clinical, laboratory and ultrasound measurements of gall bladder. In this paper we concentrated on ultrasound measurements. In the present study, the anterior wall thickness was higher in gallstone group compared to non-gallstone group but the difference did not reach statistical significance, yet it was highly significant in gallstone group in comparison to controls $(p=0.006)$. Also, the anterior wall in patients' group was significantly thicker $(p=0.046)$ when compared to the healthy children. In line with our findings, Zamir and Qurratulain [14] found a highly significant thicker anterior wall in patients with gall stones than those without gallstones in the decompensated group of cirrhotic patients $(p<0.001)$. In addition, Zhang et al., [12] found that increased thickness of gall bladder $(4 \mathrm{~mm}$ or more) is an important risk factor for occurrence of gallstones among patients with chronic liver disease. Similarly, Buzas et al., [15] conducted a study to compare gall bladder emptying in patients with chronic hepatitis $\mathrm{C}$ and in those with $\mathrm{HCV}$ related cirrhosis. They found a highly significant thicker anterior wall in patients with chronic liver disease when compared to healthy controls.

In a large proportion of patients who have gallstones by Cong et al., [12] abnormalities in gall bladder emptying are observed. Decreased motility of the gall bladder leads to incomplete emptying of bile, as evidenced by larger fasting and residual volumes. The resulting biliary stasis facilitates the development of cholesterol crystals within the gall bladder and the agglomeration of these crystals over time. Excess cholesterol is then incorporated within the sarcolemmal plasma membrane of the gall bladder smooth muscle cell, with decreased membrane fluidity, impaired contractility and impaired relaxation as a result were observed by Cong et al., [16]. In the present study, also the mean fasting volume of the gall bladder was less and the mean residual volume was more in the gallstones group compared to non-gallstones group. Also, contraction index was less in the gallstones group compared to the group without stones; however, the difference did not reach statistical significance. Shaker et al., [17] found no significant difference among patients with gallstones in comparison to patients without gallstones regarding fasting volume. They found a significant increase in postprandial volume among patients with gallstones in comparison to patients without gallstones regarding residual volume $(p<0.05)$. Jazrawi et al., [18] proved that impaired or delayed gall bladder emptying is implicated in gallstone formation by providing the time necessary for the precipitation of cholesterol crystals.
In the present study, there was no significant difference between patients with gallstones and patients without gallstones regarding the severity of chronic liver disease as assessed by the modified Child-Pugh classification ( $p=0.157)$. Zhang et al., [8] found that the frequency of gallstones increased in relation to the severity of liver dysfunction, in compensated cirrhotic patients (Child-Pugh A) it was $11 \%$ and in decompensated cirrhotic patients (Child-Pugh B,C) it was $43 \%$ with a significant trend $(p<0.001)$. The difference between our results and this study may be due to the small number of Child C patients in our study (2\%). Most of our patients were having well-compensated liver disease. In the present study, there was no significant difference between patients with gallstones and patients without gallstones regarding the duration of the illness $(p=0.358)$. Zamir and Qurratulain [10] found a highly significant difference between patients with gallstones and patients without gallstones in the decompensated group regarding the duration of the hepatic cirrhosis $(p<0.001)$. Again, this difference could be due to the short duration of disease in our patient group.

\section{Conclusion:}

Chronic liver disease in the pediatric age group is associated with sonographic gall bladder changes. The anterior wall thickness was the most significant risk factors for the development of gallstones in children with chronic liver disease.

\section{References}

1- XU LI, XIALIN G., GE YU and PUJUN G.: Gallstones in patients with chronic liver diseases. Hindawi Publishing Corporation. BioMed Research International, Article ID: 9749802, 8 pages, 2017.

2- KUMAR R., NGUYEN K. and SHUN A.: Gall stones and common bile duct calculi in infancy and childhood. ANZ Journal of Surgery, 70 (3): 188-91, 2000.

3- HERZOG D. and BOUCHARD G.: High rate of complicated idiopathic gall stone disease in pediatic patients of a North American tertiary care centre. World J. Gastroenterol., 14 (10): 1544-8, 2008.

4- HARRIS P., CHATEAU B., MIQUEL J.F., ZAVALA A., MONTES P., HERRERA J.M., ZUNIGA S., LARRAIN F., SANTOS M. and CONTADOR M.: Cholelithiasis in children: A clinical and morphological study. Rev. Med. Chil., 131 (1): 37-45, 2003.

5- PUNDIR C.S., RANI K., GARG P., CHAUDHARY R., CHANDRAN P. and KUMARI M.: Correlation between chemical composition of biliary calculi and sera of stone formers. Indian Journal of Medical Sciences, 56 (8): 373 $5,2002$.

6- SUCHY F.J., SOKOL R.J. and BALISTERI W.F.: Liver diseases in children 3 rd edition. Cambridge Medicine, 2007. 
7- ACALOVSCCHI M., BLENDEA D., FEIER C., LETIA A.I., RATIU N., DUMITRASCU D.L. and VERES A.: Risk factors for symptomatic gallstones in patients with liver cirrhosis: A case-control study. Am. Journal Gastroenterol, 98 (8): 1856-66, 2003.

8- CHAWLA A., PUTHUMANA L. and THULUVATH P.J.: Autonomic Dysfunction and Cholisthiasis in Patients with Cirrhosis. Digestive Diseases and Sciences, 46 (3): 4958, 2001.

9- KENNEDY M.: Pediatric Gallstones (Cholelithiasis): Emedicine.medscape.com: Updated Nov. 19, 2015.

10- DOOKI E.M. and NOROUZI A.: Cholelithiasis in Childhood: A Cohort Study in North of Iran. Iran J. Pediatr., 23 (5): 588-92, 2013.

11- KARAMI H., KIANIFAR R.H. and KARAMI S.: Cholelithiasis in Children: A Diagnostic and Therapeutic Approach. J. Pediatr. Rev., 5 (1): e9114, 2017.

12- ZHANG Y.1, LIU D., MA Q., DANG C., WEI W. and CHEN W.: Factors influencing the prevelance of gallstones in liver cirrhosis. J. Gastroenterol. Hepatol., 21 (9): 14558, 2006.

13- CONTE D., FRAQULLI M., FORNARI F., LODI L., BODINI P. and BUSCARINI L.: Close relation between cirrhosis and gallstones: Cross sectional and longitudinal study. Arch. Inters. Med., 159: 49-52, 1999.

14-ZAMIR BUTT and QURRATULAIN HYDER: Cholelithiasis in hepatic cirrhosis: evaluating the role of risk factors. Journal of the Pakistan Medical Association, 60 (8): 6414, 2010.

15- BUZAS C., CHIRA O., MOCAN T. and ACALOVSCHI M.: Comparative study of gall bladder motility in patients with chronic HCV hepatitis and with HCV cirrhosis. Romanian Journal of Internal Medicine, 49 (1): 37-44, 2011.

16- CONG P., PRICOLO V., BIANCANI P. and BEHAR J.: Effects of cholesterol on CCK-1 receptors and caveolin3 proteins recycling in human gall bladder muscle. Am. J. Physiol. Gastrointest. Liver Physiol., 299: G 742-50, 2010.

17- SHAKER M., MOHGA A. and EFFAT A.: Sonographic study of gall bladder function in patients with chronic liver disease and its relation to gall stone formation. Sci. Med. J. ESCME, 9 (2), 1997.

18- JAZRAWI R., PAZZI P., PETRONI L., PRANDINI N., PAUL C., ADAM J., GULININ S. and NORTHFIELD T.: Postprandial gall bladder motor function: Refilling and turnover of bile in health and in cholelithiasis. Gastroenterology: 109: 582-91 (2), 1995.

\section{تفيرات بالموجات فوق الصوتية للمرارة فى الأطفال الذين يعانون من أمراض الهوفيد الهبد الهزمنة}

\footnotetext{
تعد آمراض الكبد المزمنة فى الآطفال مشكلة شائعة. وعلى الرغم من آن هذه الآمراض قد تكفن مصحوبة بآعراض بسيطة إلا آنها فى في آحيان آخرى قد تكن خطيرة وتؤدى إلى الوفاة خاصة فى البلدان النامية.

تهلف دراستنا إلى تقييم التغيرات فى تصوير المرارة بالموجات فقق الصوتية عند الآطفال المصابين بآمراض مزمنة فى الكبد مقارنة

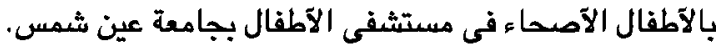

شملت هذه الدراسة مائة وخمسة وعشرين طفلاً، بما في ذلك مائة طفل مريض بآمراض الكبد المزمنة وخمسة وعشرين طفلاً يتمتعون

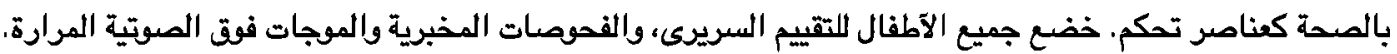

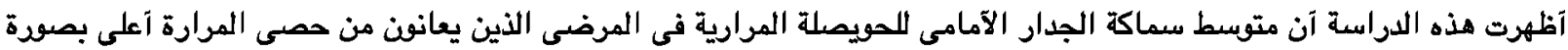

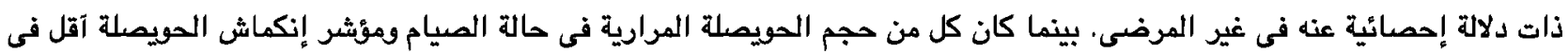

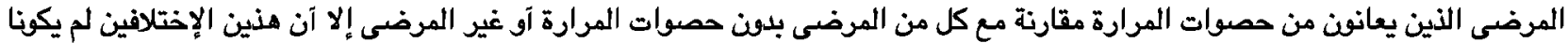

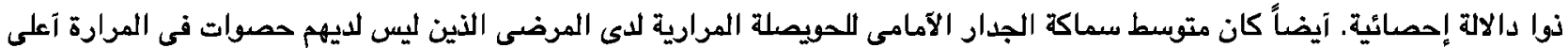
من غير المرضى إلا آن هذا الإختلاف لم يكن ذان دان دلالة إحصائية.

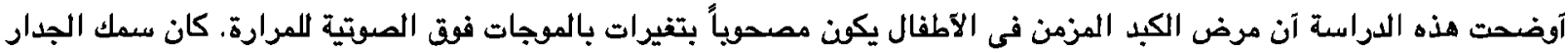

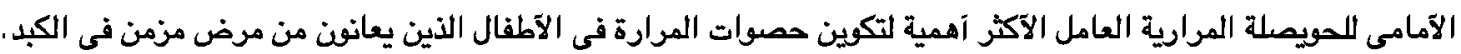

